\title{
Gamification in teaching Maintenance Engineering: A Dutch experience in the rolling stock management learning
}

\author{
Martinetti, Alberto ${ }^{\text {a }}$; Parada Puig, Jorge Eduardo ${ }^{\text {b; Oude Alink, Charlotte }}{ }^{\text {a }}$, Thalen, \\ Jos $^{c}$ and van Dongen, L.A.M. ${ }^{\text {a,d }}$
}

${ }^{a}$ Design, Production and Management Department, University of Twente, The Netherlands ${ }^{\mathrm{b}}$ Departamento de Tecnología y Diseño, Universidad de los Andes, Venezuela

${ }^{\mathrm{c}}$ Invocate, The Netherlands ; ${ }^{\mathrm{d}}$ Nederlandse Spoorwegen (NS), The Netherlands.

\begin{abstract}
The aim of this study is to evaluate the application of an innovative serious game, based on the asset management of rolling stock, in the training of future maintenance engineers within the master course in mechanical engineering at the University of Twente. The Logistic Support Game (LSG) is a serious game developed together with Netherlands Railways (Nederlandse Spoorwegen, NS) and Invocate (design firm) as a tool to simulate the maintenance operations of a fleet of trains. The simulation shows four perspectives: the operations manager, the asset manager, the maintenance manager and the financial manager.

The three goals of this innovative training are the improvement of student engagement in the learning process, the increas of active cooperation between students with different roles in a group, and the opportunity to receive feedback on decision making. To indicate achievement of these goals, they are linked to the basic needs of learning: competence, relatedness and autonomy.
\end{abstract}

A total of thirty six students played the serious game in two different sessions. At the end of each session, a survey is collected for game based learning assessment. Results suggest that the serious game has a positive impact on student engagement, cooperation, and helps transfer course contents.

Keywords: Serious Game; Gamification; Emerging Technologies; Maintenance Engineering; Asset Management; Master students; 


\section{Introduction}

Games have been used for centuries for purposes as broad as forecasting, learning or entertainment. Game Based Learning (GBL) refers to the use of games as tools to support learning. Introducing game mechanics --gamification-- through a serious gaming tool aims to transfer course content in a way that is engaging, active and fun.

There is a large amount of empirical evidence of the positive outcomes of playing games. These outcomes can be knowledge acquisition, perceptual, cognitive, physiological, social and behavioural (Boyle et al., 2016). Results of the extensive survey by Boyle et al. (2016) also show the growing popularity of games for learning science, technology, engineering and math subjects. Moreover, serious games can be beneficial to student engagement, cooperation, and help transfer course contents. Section 2 further discusses benefits of GBL with a strong attention to board games, less represented in the literature than computer games.

The purpose of the research is to discuss the experiences with one such tool for teaching maintenance engineering master course at the University of Twente. The classroom experience is based on a serious game called the Logistic Support Game (LSG), developed in collaboration with Invocate and the Netherlands Railways (Parada Puig, 2015, Ch. 7). The game is a physical board game through which students make management decisions to maintain a fleet of rolling stock. Learning assessment is addressed as embedded formative assessment in the game, and external summative assessment in the form of a feedback session. The aim and the main features of the game are detailed in Section 3. Data from two different sessions with a total of thirty six students is collected and analysed. Section 4 discusses the results. Finally, section 5 presents the research conclusions.

\section{The benefit of using serious games}

Many different results are found about the effectiveness of Game Based Learning (GBL) (Crocco, Offenholley \& Hernandez, 2006); it is widely accepted that GBL can be a motivator for students (Garriset et al., 2002) and it has the potential to support deeper learning (Crocco et al., 2006). Depending on the design of the serious game, GBL can be linked to all three of the basic needs of learning of Deci \& Ryan (2002): competence, relatedness and autonomy.

Competence is about the feeling of being efficient (Deci \& Ryan, 2002). Receiving feedback can support the students in this feeling. Furthermore, it is important to include feedback in the design of the game, to help the students to immediately know the result of their actions (Hulme, Kasprzak, English, Moore-Russo, \& Kemper, 2009). According to Westera, Nadolski, Hummel \& Wopereis (2008), this type of feedback is called "strategic 
performance feedback" and it gives the students feedback on their progress in the game instead of directly on their learning outcomes.

Increasing relatedness can be done in several ways. Firstly, by letting the students feel they are part of a group/community (Deci \& Ryan, 2002; Smith, Sheppard, Johnson \& Johnson, 2005). Secondly, by relating the educational settings to the real world (Deciand \& Ryan, 2002). Thirdly, adopting real cases. Callaghan et al. (2013) describe the positive effects on the engagement of students by implementing a serious game or simulation game in which the students collaborate in groups and, or if they are in competition with each other (Westera et al., 2008; Hulme et al., 2009).

The autonomy of the students relates to the perception of amount of personal say they have in their own learning (Deci \& Ryan, 2002). In a serious game, the students play by rules of the game but they can determine their own actions feeling freer to experiment with different decisions and to practise their skills for the real world (de Freitas, 2006), due to the lack of (real) consequences in a game (Hulme et al., 2009).

Based on the links between the basic needs for learning and student engagement, GBL definitely is an interesting method in teaching students. It comes down to the design of the game.

\subsection{Benefits of Game Based Learning}

Research shows that games that are designed for a specific course are more efficient then commercially developed games (de Freitas, 2006). Several serious games are computer based and evidence for the effectiveness of board games in higher education is limited (Lean, Moizer, Towler \& Abbey, 2006). But, it is known they are implemented in different disciplinary fields (Lean et al., 2006). One of the positive examples is the board game developed and researched by Holweg \& Bicheno (2002). Their experiences were that the impact of the chain supply game was more effective than general developed educational games.

"They had three reasons why they think the game was a success in an educational setting. Firstly, the results and learning points are directly transferable into the practice. Secondly, the direct interaction of the players and their direct experience has proven to be a great advantage in helping to explain key concepts to the players. Thirdly, the specific simulation model allows the players to experience the system from a different perspective than the one of their own company by playing any other station in the system" (p.173).

However, does this also apply for master students in engineering programmes? According to Callaghan et al. (2013), Hulme et al. (2009) and Clapper (2016) this is the case. When specifically looking at engineering education it is stated that: 'it is vital for students to have peer support and to be active learners, not only so that more of them learn the material at a 
deeper level, but also so that they get to know their classmates and build a sense of community with them' (Smith, et al., 2005, p.11).

\section{The Logistic Support Game (LSG)}

The LSG was developed to explore and support new asset acquisition strategies. The game addresses the primary question of whether to buy assets that match an existing maintenance infrastructure, or (re)-design the maintenance infrastructure in such a way that it matches a newly acquired asset. In this context, the game helps by providing an overview of the complexity of managing assets and their maintenance infrastructure. The LSG allows players to safely explore and evaluate various acquisition strategies and scenarios.

While the game was originally intended for decision makers (i.e. management), this research also applies it in education. In this context, the focus of the game is not on strategic decision making, but on gaining insight about the complexity of the supply chain, and about the roles of each stakeholder involved. This application is further discussed in Section 4.

\subsection{Game components}

The LSG is a board game consists of four primary components: a game board, train cards, maintenance stations and the maintenance schedule. The game board features 3 fictional cities (A, B and C) connected by train tracks. The board is used to visualise the allocations of trains to each route (i.e. a connection between city A and B, B and C or C and A) and the distribution of maintenance stations within the infrastructure. Train cards represent different types of trains, each with its own price, capacity (number of passengers), reliability and maintenance profile. Maintenance stations represent repair locations for trains. They are allocated to a specific location on the game board, and are equipped with a specific set of repair tools chosen by players during the game. The maintenance schedule is used to plan the maintenance and overhauls of the entire fleet of trains optimising the uptime as a whole.

\subsection{Gameplay and strategic challenges}

The game is played by a group of at least 4 players and 1 trained facilitator. Each player is assigned to a specific role of rolling stock operations manager, fleet manager, maintenance operations manager and financial manager, that is linked to each game component. Together, the team is responsible for transporting passengers between cities A, B and C on the game board. A game session features one or more scenarios: a configuration of maintenance stations, a fleet of trains and a maintenance schedule. In each turn the team has to find a balance between the passenger capacity demand (which may vary throughout the scenario), their train fleet and the maintenance infrastructure. 
Each turn consists of the following steps: investment, doing maintenance and collecting revenues. Investment is based on the current settings and passenger capacity requirements, the team has the opportunity to invest, for instance in additional maintenance stations, addition tooling or new trains. Doing maintenance implies that all trains requiring maintenance can be repaired or overhauled, assuming sufficient maintenance resources are available. The team collects revenues for the number of passengers they transport. Passengers can only be transported on available trains, and trains can only be available whenever sufficient maintenance resources are available. The revenue depends on the availability of the train fleet. The next turn begins after collecting revenues.

The team's primary objective is to achieve a stable (or even profitable) system; revenues should cover investments and maintenance costs. To achieve this, the team has to consider the maintenance profile of each train card (regular repairs, overhauls and end-of-life), the features of the maintenance station ('A-type' train can be repaired only in 'A- type' repair stations) and customer satisfaction (which affects the long-term passenger demand, and therefore potential revenues). Teams can reflect on their strategies and decisions in a postgame discussion, using the scoring sheets as a starting point. The discussion explicitly relates turning points in the scores to decisions made by the team, and asks the team members to reflect on their actions as external summative assessment.

\section{Experience from the master specialization in Maintenance Engineering}

The aim of LSG is to simulate the management of a specific asset (rolling stock) thorough its entire life cycle and to evaluate possible new strategies within the company. However, as highlighted in Section 2, above, serious games also provide remarkable pedagogical and educational opportunities. Games can transfer right contents and important information through active learning. Active learning improves student engagement during the lecture, and increases the cooperation between the students within the group having different roles in order to achieve a specific task.

\subsection{Better engagement, understanding and competition: the game session organization}

The LSG sessions are planned for a duration of 90 minutes. Each session is split into two parts, each consisting of 45 minutes. The first part begins by transferring the message, information and game rules to the students during the first 30 minutes, and ends by making students play a first test round of 15 minutes with the help of the facilitators. One facilitator is assigned to each group. In the second part of the session, participants play the game independently during 45 minutes. During the second part, facilitators can only ensure that the game rules are followed by each group. To encourage students playing seriously, and to increase the fun, the second part of the game session is organised as a competition between groups. The results of every game round are tracked by the facilitators of each group and 
shown on the main screen of the room. Figure 1 displays one game session with the score and investment results.
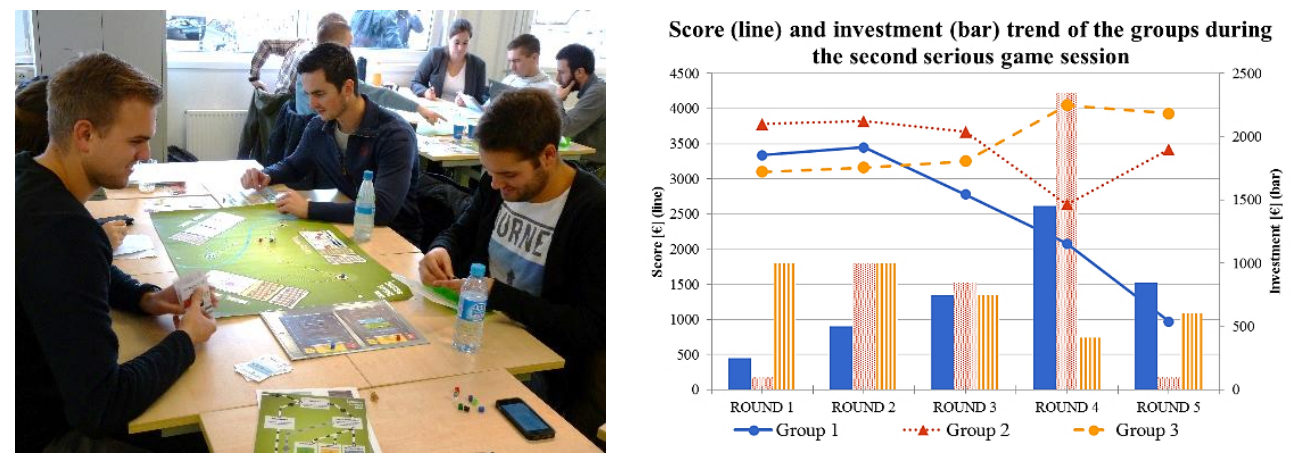

Figure 1. A moment during the second game session (left)

and the score and investment results after 5 rounds (right)

Data is collected from two sessions. In the first session (21 students) 5 groups played the game and in the second session (15 students) 3 groups played the game. Each group is formed by 4-5 students. As highlighted in the score trend in Figure 1 (right), every group usually has its own starting strategy with different types of investment in terms of trains and maintenance workshop acquisitions. It is interesting to notice the effects of these initial strategies on the final scores. For instance, Group 3 starts with a high investment strategy (backup trains and maintenance workshop acquisition) and never experiences financial troubles in the later rounds of the session without risking bankcrupcy.

\subsection{Evaluation on the serious game sessions: a students' survey}

Even though the informal feedback of the students is extremely positive both for the level of engagement and for the received learning information, a more scientific method to assess those impressions is adopted. A survey is conducted at the end of each session. Even if the data set (36 students) is not statistically robust, it can give an indication about the perceived engagement of the users, and about the performance of active learning in terms of provided information on the asset management study topic.

The questionnaire had 6 closed questions based on a Likert scale version (range of value from 1-very neagtive to 5-very positive) as psychometric tool to grade the responses. The feedback results of the two game sessions are summarised in the spider graph of Figure 2. The values represent the percentage of the possible score reachable for every posed question.

As shown, the distributions of the obtained results in the first and second session are similar, suggesting a homogenous perception and a strong coherence among the opinions of the students. An interesting result to discuss is the shared suggestion to not extend game 
session; according to the survey, the time session was enough to engage better and to transfer the right information in terms of competences and learning goals.

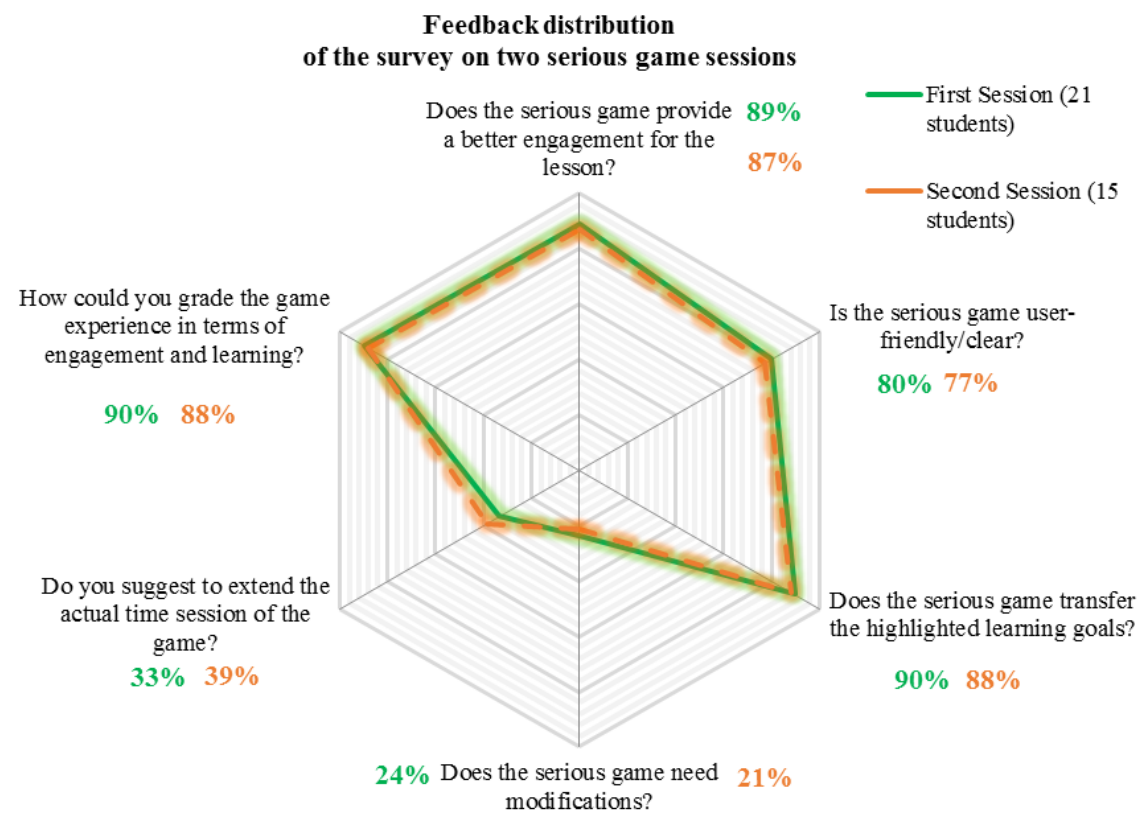

Figure 2. Feedback distribution of survey proposed to the students in each session

\section{Conclusion and further applications}

GBL offers indeed a huge tool to improve the active learning in higher education as mechanical engineering course. The results obtained during the LSG sessions suggest that the game greatly increases the engagement, simulates a collaborative socialization, and transfers, at the same time, proper educational competences. These competences are related not only to rolling stock maintenance issues, but in general to the problems related to asset management. Moreover, the serious game offers a relevant opportunity to let the students apply and experience different strategies, forcing them to make mistakes, and to understand the reasons behind them during the discussion sessions. Similar to the results from Holweg \& Bicheno (2002), the students expressed that their understanding of the key concepts in the process is enhanced by playing the game. When linking the design of the game to the basic needs of learning, the positive results can easily be explained. The collaboration within a team and competition between teams makes the students related to their peers, and the subject of the game relates it to the real world. The strategic performance feedback that students receive about their progress during the game make the students feel competent (or shows them they still need to practise). Concerning the autonomy of the students, in the 
results it can be seen that group 1 felt free enough to take changes. The group chose not to invest and save money (taking a different strategy than group 2 and 3). Unfortunately, for that group this decision almost caused bankruptcy. Luckily it is only a game.

Further research should focus the attention on the evaluation of several serious games to use during the same master specialization. This would allow us to investigate pedagogical strengths and weaknesses of the extensive use of GBL on the learning capacity of students.

\section{References}

Boyle, E. A., Hainey, T., Connolly, T. M., Gray, G., Earp, J., Ott, M., Lim, T., Ninaus, M., Ribeiro, C., Pereira, J. (2016). An update to the systematic literature review of empirical evidence of the impacts and outcomes of computer games and serious games. Computers and Education, 94, 178-192.

Callaghan, M.J., McCusker, K., Lopez Losada, J., Harkin, J., \& Wilson, S. (2013). Using Game-Based Learning in Virtual Worlds to Teach Electronic and Electrical Engineering. IEEE Transactions on Industrial Informatics, 9(1), 575-584.

Clapper, T.C. (2016). Multidisciplinary Enjoyment and Learning in Simulation \& Gaming. Simulation \& Gaming, 47(4), 399-402.

Crocco, F., Offenholley, K., \& Hernandez, C. (2006). A Proof-of-Concept Study of GameBased Learning in Higher Education. Simulation \& Gaming, 47(4), 403-422.

Deci, E. L., \& Ryan, R. M. (2002). Handbook of self-determination research. University Rochester Press.

De Freitas, S. (2006). Learning in immersive worlds: a review of game-based learning. Bristol: Joint Information Systems Committee. Retrieved from: http://www.jisc.ac.uk/media/documents/programmes/elearninginnovation/gamingreport _v3.pdf.

Garris, R., Ahlers, R., \& Driskell, J.E. (2002). Games, motivation, and learning: A research and practice model. Simulation \& Gaming, 33(4), 441-467.

Holweg, M. \& Bicheno, J. (2002). Supply chain simulation - a tool for education, enhancement and endeavor. International Journal Production Economics, 78, 163-175

Hulme, K., Kasprzak, E., English, K., Moore-Russo, D., \& Kemper, L. (2009). Experiential Learning in Vehicle Dynamics Education via Motion Simulation and Interactive Gaming. International Journal of Computer Games Technology (2009).

Lean, J., Moizer, J., Towler, M., \& Abbey, C. (2006). Simulations and games: Use and barriers in higher education. Active Learning in Higher Education 7(3), 227-242.

Parada Puig, J. E. (2015). Serviceability of passenger trains during acquisition projects. $\mathrm{PhD}$ Thesis, University of Twente.

Smith, K.A., Sheppard, S.D., Johnson, D.W., \& Johnson, R.T. (2005). Pedagogies of Engagement: Classroom-Based Practices. Journal of Engineering Education, 94(1), 87101.

Westera, W., Nadolski, R.J., Hummel, H.G.K. and Wopereis, I.G.J.H. (2008). Serious games for higher education: a framework for reducing design complexity. Journal of Computer Assisted Learning, 24(5), 420-432. 